\title{
Comunicação Organizacional: o contexto e o texto das Relações Públicas
}

\author{
Organizational Communication: \\ the context and the text of Public Relations
}

\author{
Comunicación Organizacional: el contexto \\ y el texto de las Relaciones Públicas
}

\section{Sidinéia Gomes Freitas}

- Professora titular da Universidade de São Paulo

- Pós-doutora pela Universidade Fernando Pessoa (Portugal).

- Livre-docente, doutora e mestre em Ciências da Comunicação pela Escola de Comunicações e Artes da Universidade de São Paulo (ECA-USP)

- Professora do Programa de Pós-Graduação em Ciências da Comunicação da ECA-USP e da Fundação Escola de Comércio (Fecap)

- Autora de diversos artigos e capítulos de livros

- Ex-presidente do Conselho Federal dos Profissionais de Relações Públicas (Conferp)

- Ex-coordenadora da Comissão de Especialistas de Ensino em Comunicação na Sesu/MEC

- Consultora de Comunicação Organizacional, prestou serviços a diversas empresas e entidades

- sidialogo@gmail.com; sidineia@usp.br 
Este texto aponta o papel das Relações Públicas no contexto da Comunicação Organizacional, com base nas interfaces oriundas da formação do comunicador na atualidade. Indica novas demandas para o exercício de funções de gestão e as contribuições das Ciências Humanas que agregam valor ao desempenho profissional.

PALAVRAS-CHAVE: INTERFACES • FORMAÇÃO • COMUNICADOR • COMUNICAÇÃO ORGANIZACIONAL • RELAÇÕES PÚBLICAS • GESTÃO

\section{Abstract}

This text points out the role of Public Relations in the context of interfaces that are based on Organizational Communication and on the making of a communicator in current circumstances. It signals new demands for the exercise of management and the contributions of Human Sciences that add value to professional performance.

KEYWORDS: INTERFACES • TRAINING • COMMUNICATOR • ORGANIZATIONAL COMMUNICATION • PUBLIC RELATIONS • MANAGEMENT

Resumen

Se señala el papel de las Relaciones Públicas en el contexto de la Comunicación Organizacional, con base en las interfaces originarias de la formación del comunicador en la actualidad. Se indican también las nuevas exigencias para el ejercicio de las funciones de gestión y las contribuciones de las Ciencias Humanas, que agregan valor al desempeño profesional.

PALABRAS CLAVE: INTERFACES • FORMACIÓN • COMUNICADOR • COMUNICACIÓN ORGANIZACIONAL • RELACIONES PÚBLICAS • GESTIÓN 
A s Relações Públicas, na formação de seus profissionais, priorizam funções inerentes à gestão da Comunicação Organizacional. Não se atêm apenas a questões predominantes da área. Demonstram lucidez quando alertam para os pré-requisitos exigidos já nos processos decisórios e quando do planejamento dos investimentos que serão feitos em Comunicação.

Comunicação Organizacional e Relações Públicas:

demanda de novos perfis

Antes de decidir sobre a aprovação de determinado projeto, é fundamental que ele esteja alicerçado em dados de pesquisa quantitativa e qualitativa, que se conheça o ambiente nos níveis macro- e micropolítico (SIMÕES, 2001) em que se desenvolverá a Comunicação e, principalmente, que os integrantes do processo decisório tenham sensibilidade para entender o papel da Comunicação Organizacional. É preciso, ainda, compreender a função política da atividade de Relações Públicas, sob pena de transformarmos comunicadores em executores de tarefas que visam ludibriar e manipular os diferentes públicos envolvidos nos negócios das organizações. De fato a atividade Relações Públicas se desenvolve em pelo menos duas bases epistemológicas: a técnica e a política. No caso das organizações com declarada finalidade comercial, a micropolítica interage com a macropolítica. No primeiro setor é a macropolítica que predomina no complexo cenário de gerenciamento. De igual modo, o terceiro setor também requer funções de gerenciamento em organizações hoje em franco desenvolvimento.

As funções técnicas de gestão em Comunicação se aprimoraram e se solidificaram nos últimos anos. Nessa vertente epistemológica houve produção acadêmica bem orientada, com maior peso para as Ciências da Administração. Assim, no processo de decisão tudo, ou quase tudo, é resultado de planejamentos bem elaborados por Relações Públicas. O profissional da área elabora diagnósticos e prognósticos; classifica públicos; elabora planos com programas detalhados; incorpora a criatividade nas tarefas; define objetivos; analisa cenários; efetua benchmark; indica pontos fortes e pontos fracos das organizações; equaciona recursos necessários; prevê a utilização das mídias adequadas; elabora orçamentos; planeja todo o processo para o gerenciamento das funções sobejamente conhecidas como gestoras da Comunicação. Está ciente de que depende minimamente da Publicidade e da Propaganda, da Imprensa, do Marketing e das políticas de gestão de pessoas.

O papel e as funções de gestor lhe são pertinentes e concernentes com sua formação. Não é tarefa fácil gerenciar com eficiência e eficácia todo o processo da Comunicação Organizacional. Demanda um conjunto de competências e habilidades. 
A visão dos olhares sensíveis em tempos de globalização identifica com certa rapidez os conteúdos de modelos, mas, para além dos modelos e do marketing, conhecer os princípios da cultura organizacional, da sociossemiótica, da política enquanto exercício do poder, certamente auxiliará a visão estratégica, agregando valor à técnica. Dominam-se técnicas de gestão. Mas em que cenário e com quais políticas de gestão?

Recomenda-se visão multidisciplinar àqueles detentores de olhares sensíveis. Abordando a visão ingênua e visão crítica dos profissionais de relações públicas no que tange a mercado de trabalho, Simões (2007) alerta que a visão ingênua acerca de Relações Públicas vive se autodesvalorizando. Mas o mercado deseja quem resolve seus problemas com sensibilidade, conhecimento do mundo dos negócios e muito planejamento. Muitos comunicadores, quando inseridos no mercado de trabalho, buscam o olhar e os conhecimentos de Relações Públicas. Na formação, principalmente nos cursos de especialização, aprimoram-se profissionais egressos de nossos supostos concorrentes, apesar da demanda e da tradição que o mercado lhes atribui.

Corroborando o olhar sensível de Simões, que o identifica como "visão crítica", os bons profissionais ocupam espaços independentemente de melhores ou mais precisas designações no campo da Comunicação. Percebem nichos para atuação eficiente e não se preocupam em ficar discutindo questões de registro profissional, "pois são poucos ou quase nada, os países que o utilizam" (SIMÕES, 2007, p. 26).

Durante a formação dos primeiros egressos no campo das Relações Públicas, os programas de relações com os empregados eram considerados fundamentais para o início de projetos mais amplos que objetivassem a imagem e o conceito favorável de qualquer organização. Na década de 1970 esses programas não mereciam a menor atenção de parte das organizações. Não importa a terminologia, mas o fato é que com o nome de Comunicação Interna, os programas de relações com os empregados adquiriram valor.

Para melhor desenvolvermos a Comunicação Interna, ou para bem administrar relacionamentos, um olhar sensível percebe que não bastam apenas habilidades de gestão. Outros conhecimentos são necessários, tais como o que se escreve e o que se discute em termos de cultura organizacional, de liderança, de políticas de gestão de pessoas - que incluem as paixões humanas (ciúme, inveja, assédio moral etc.) e questões de relacionamento entre humanos.

O olhar crítico e sensível permite afirmar que existe avanço para além das questões de gerenciamento da Comunicação quando outros saberes dialogam, dada a complexidade de todo o composto organizacional. 
É preciso avançar no aprofundamento nas questões de gerenciamento dos relacionamentos com diferentes objetivo,s que incluem problemas maiores da sociedade, os da responsabilidade social, da sustentabilidade, da ética, enfim da estrutura política de todo o processo da Comunicação.

\section{Proposta: assumir um olhar crítico e sensível}

O constante incômodo do olhar sensível fez percorrer diferentes caminhos. É a construção de um novo objeto a ser pesquisado e cuja complexidade perpassa a cultura que determina valores, ética, moral, definindo e redefinindo constantemente missão e valores. Determinando o exercício do poder, a política em nível macro e na micropolítica estabelecida no corpo das organizações (SIMÕES, 1995, 2006) não escapa das paixões, dos sentimentos. Discorrendo acerca de utopia na atividade de Relações Públicas, Simões (2006, p. 103) afirma:

Nesse outro lugar, o sistema de governo existente é a democracia. É nesse âmbito que o ser humano pode expressar seus desejos, seus sonhos e lutar por eles. É o lugar de onde se pode organizar com outros e influenciar organizações e governos que não estão atuando conforme seus interesses. O povo deste País se libertou da pressão, da cultura do populismo e do medo do exercício da cidadania. Desde há muito são cidadãos, não mais sujeitos. Têm tomado consciência de que devem lutar por extinguir esse desejo antigo das ditaduras, tanto explícitas do poder de alguns quanto explícitas em seu inconsciente.

noções de consenso e de conflito para Landowski (2005)implicam núcleos de significações e de articulações lógicas e um lado relação de identidade, de compatibilidade ou de conjunção entre dois ou mais termos relações de diferença, de incompatibilidade no caso dos discursos políticos (inclusive no recorte metodológico da política organizacional), remete a um grande número de expressões - cooperação, associação, dependência, dominação, hostilidade, rivalidade, representação - que designam pequenas encenações entre sujeitos políticos. Segundo o autor, no contexto político, os enunciados têm alcance programático na medida em que aparecem como "realizáveis" comprometendo os sujeitos estratégias que em diferentes ideologias possibilitam ou impedem que alcancem seus fins ao mesmo tempo em que manifestam, em seus discursos, o querer constitutivo dos sujeitos. Empenham, geralmente com suporte em suas lideranças, as capacidades do fazer nas organizações. Eis a dimensão sensível, inteligível que é preciso desvendar.

Correlacionar o uso de tais expressões em campanhas internas ou programas de sustentabilidade das organizações globalizadas é um bom exercício para um olhar crítico e sensível que pode agregar valor. 


\section{Referências}

LANDOWSKI, Eric. A sociedade refletida: ensaios de sociometria. São Paulo: Educ/Pontes, 1992

SIMÕES, J. Roberto Porto. Relações públicas ingênua e crítica. In: DORNELLES, Souvenir M. Graczyk. Relações públicas: quem sabe faz e explica. Porto Alegre: Edipucrs, 2007.

Relações públicas e micropolítica. 2. ed. São Paulo: Summus, 2001.

Informação, inteligência e utopia: contribuições à teoria de relações públicas. São Paulo: Summus, 2006.

94 COMUNICAÇÃO ORGANIZACIONAL: 0 CONTEXTO E 0 TEXTO DAS RELAÇÕES PÚBLICAS • SIDINÉIA GOMES FREITAS 